\title{
Analysis of the surface-roughening phenomenon in P-added bake-hardened steel sheets
}

Nam Hoon Goo ${ }^{*}$ and Chungu Kang ${ }^{\dagger}$

\author{
${ }^{*}$ Correspondence: \\ namhgoo@hyundai-steel.com \\ ${ }^{\dagger}$ Equal contributors \\ Sheet product design group, \\ Hyundai Steel Co., North Industrial \\ Str. 1400, 343-823, Dang Jin 343-823, \\ South Korea
}

\begin{abstract}
The surface-roughening problem with phosphorous-added bake-hardened steel sheets was investigated. Surface undulation in the sheets occurs after 2\% to 3\% deformation during press forming action and disappears with further deformation over 10\%. The roughened sheets exhibit heterogeneity of the elemental P (phosphorous) distribution, and the segregation of $P$ increases the hardiness of ferrite grains locally. This local strengthening of ferrite grains causes a concentration of strains in the other ferrite regions that do not contain the elemental P-segregation. The strain concentration is because of the surface undulation in the sheets under small amount of straining. The evolution of the deformation texture and the corresponding Lankford values are shown using a series of viscoplastic self-consistent (VSPC) simulations, which indicated that a strong \{554\}[225] texture develops, and subsequently, the Lankford value increases in the non-segregated ferrite region. The higher Lankford value makes it more difficult to deform the sheet in the through-thickness direction. The different texture developments of the segregated and segregation-free regions are the main causes of the disappearance of the surface undulation with a high amount of plastic straining greater than $10 \%$. Finally, we conclude that the segregation of $\mathrm{P}$ inherited from hot band affects the plastic deformation and developed textures of the thin steel sheets.
\end{abstract}

Keywords: Ghost line defect; Plastic anisotropy; Surface roughening; Deformation texture

\section{Background}

The surface quality of steel sheets is an important issue in addition to their mechanical formability. In particular, the sheets used for outer panels in automobile manufacturing are required to have perfect surfaces. Most defects of steel sheets are types of physical or chemical damage originating from various processing issues. Sliver marks are due to uncontrolled non-metallic inclusions during steel making and the continuous casting mold [1]. Ashes of zinc-aluminum vapor in the molten galvanizing pot can leave physical defects on the sheet surface [2-6]. Damage to working and back-up rolls in hot and cold rolling process are also major causes of surface defects, with this damage being transferred from the roll surface onto the sheet $[7,8]$. The defects mentioned above are clearly observed by the naked eyes or with automatic image detectors. A manufacturer can screen for most defects in the final processing line. However, the surface-roughening

(c) 2014 Goo and Kang; licensee Springer. This is an Open Access article distributed under the terms of the Creative Commons Attribution License (http://creativecommons.org/licenses/by/4.0), which permits unrestricted use, distribution, and reproduction in any medium, provided the original work is properly credited. 
problem discussed here is not detected in as-produced sheets. The problem appears after the sheets have been pressed into an appropriate car body panel. The defect area is also confined in a region that has undergone a small amount of plastic deformation. A deep-drawn or highly stretched region does not exhibit this types of surface defect. The roughened surface means that the series of surface undulations occur in an out-of-plane direction. Because these defects appear suddenly in the initial stage of plastic deformation and disappear after sufficient plastic deformation, it is known as the 'ghost line' defect. This roughened surface usually leaves striped bands on the panel, and conventional painting does not cover these bands.

The cause of this roughening can be classified into external and internal causes. The external causes are certain imperfections of mechanical contacts in press forming dies, including mismatches between forming tools, frictional conditions, and corroded die surfaces, and these imperfections affect surface plastic flow [9]. Of these imperfections, the frictional mismatch by which roughened wrinkling stripes are generated is mainly problematic. This mismatch is not related to intrinsic material properties and can be solved easily by optimization of the forming process. In contrast, microstructural defects inside the metal sheet such as dislocation bands, misoriented grain colonies, and hard precipitate particles can result in surface roughening during plastic deformation [10-15].

The structural defects originate from mismatches between atomic layers or crystallographic planes. An elastic distortion field exists in the vicinity of the defects. Inhomogeneous strains propagates the entire surface as a response to applied stress because the steel material for a car body panel is such a thin sheet ( 0.5 to $0.8 \mathrm{~mm}$ thickness) that its entire plastic deformation through thickness can be affected by localized strain fluctuation.

Recent studies on surface roughening considering the intrinsic microstructural aspects have focused on understanding the dependencies of the strain localization on the grain size, texture, and second-phase inclusion. Becker [16] investigated the strain localization of aluminum sheet surface and observed that the strain localization was caused by the effects of grain size difference, texture, and strain-hardening inhomogeneity. The grain-scale surface roughening was mainly generated by the presence of the different crystallographic orientations in a polycrystalline body. Schaefer et al. [17] studied the texture evolution in the vicinity of hard second phases during cold deformation. Their FEM simulation reveals that the evolution of plastic inhomogeneity appears to be over $45 \%$ of cold working, and the texture component close to the hard phase changes to a characteristic one with a $45^{\circ}$ rotated cube. These texture simulations are also consistent with the experimental observations.

The large areal surface roughening in this paper is observed directly after the press forming action and has been a chronicle problem for panel making of car bodies. In addition, there have been many debates about whether this problem is caused by external conditions in the press facility or intrinsic microstructural defects [2,18-29]. To circumvent the external causes, we conducted uniaxial tensile tests with very small strain and compared the surface state with the surface of the deformed sheet after press action. In addition to the tensile grips, we prepared the clean surface of the specimen in the gauge area and investigated the surface roughening. The clean and non-contact gauge areas ensure that the external factors are completely excluded. Microstructural analyses were also performed on the roughened surfaces to clarify the mechanism by which the defects form. The aim of this work was to determine the main cause of the line defects that 
appear directly after cold deformation. To accomplish this task, we focused on investigating the differences in the microstructures and deformation textures between the normal and defective areas.

\section{Experimental}

We used cold-rolled sheets of P-added bake-hardened steel of $340 \mathrm{MPa}$ grade. The sheets were manufactured in a $0.7-\mathrm{mm}$-thick coil at Hyundai Steel Dangjin works. The coldrolled coils were made from $2.7-\mathrm{mm}$ gauge hot band, which came from continuously cast slabs. The chemical composition of the coils is given in Table 1 . The sheets were then annealed in an industrial annealing furnace with a soaking temperature of $830^{\circ} \mathrm{C}$, and line speed of $230 \mathrm{mpm}$ (meter per minute). The final annealed microstructure consisted of clean ferrite grains with $\mathrm{NbC}$ precipitates.

The test samples were acquired from coiled sheets placed into a $50 \times 210 \mathrm{~mm}$ plate for deformation tests. The deformation tests were performed with a low-speed tensile testing machine, with a cross head speed of $2.0 \times 10^{-3} \mathrm{~mm} / \mathrm{s}$. The surface and microstructural characteristics were investigated after uniaxial tensile elongation.

The surface roughness profile was obtained using a contacting surface scanner (Mitutoyo, CS-5000, Aurora, IL, USA). The scanning area covered $10 \times 10 \mathrm{~mm}^{2}$, and the scanned signals were treated with a fast Fourier filter $(S / N=100)$ to remove undesirable noise signal.

Structural morphology and texture analyses were performed using an optical microscope $(\mathrm{OM})$ and scanning electron microscope (SEM) each equipped with quantitative energy dispersive X-ray spectrometry (EDX) and electron backscatter diffraction (EBSD). A field emission type SEM (JSM-7000F, JEOL Ltd., Akishima-shi, Japan) was operated at an acceleration voltage of $25 \mathrm{kV}$ for analyses. The OIM EBSD program (TSL/EDAX Corp.) was used to post process the numerical EBSD data. Transverse sections of the sheets were prepared after metallographic polishing and etching. To remove significant polishing defects, the sectioned samples for the EBSD analyses were also polished with fine alumina powders of $0.1 \mu m$ diameter.

A solution of $1 \%$ hydrochloric acid and picric acid mixture was selected for the etchant. The etchant was appropriate for obtaining a clear contrast between the areas of the elemental segregation and non-segregation. To determine precisely which element was segregated near the sheet surface, the regions with etching contrast were probed using an electron microprobe. The electron probe analyzer used here was a JEOL (JSX-8230,

Table 1 Chemical composition and dimension of steel sheets

\begin{tabular}{lc}
\hline & Value \\
\hline Chemical composition $[w t \%]$ & \\
$\mathrm{C}$ & 0.002 \\
$\mathrm{Si}$ & 0.01 \\
$\mathrm{Mn}$ & 0.5 \\
$\mathrm{P}$ & 0.05 \\
$\mathrm{~S}$ & 0.010 \\
$\mathrm{Nb}$ & 0.015 \\
$\mathrm{~N}$ & 0.0050 \\
Hot-rolled thickness $[\mathrm{mm}]$ & 2.7 \\
Cold-rolled thickness $[\mathrm{mm}]$ & 0.7 \\
\hline
\end{tabular}


JEOL Ltd., Akishima-shi, Japan) model equipped with five wavelength dispersive spectrometers. Using this setup, a two-dimensional quantitative elemental distribution was obtained. Peak calibration for all elements of interest was performed before the segregated specimen was probed. For phosphorus, the apatite (Ca-phosphate) standard was used with replacement of the steel standard with an appropriate composition. The other peak intensities stem from elements such as $\mathrm{Mn}, \mathrm{P}, \mathrm{Ti}$, and $\mathrm{Nb}$, which were calibrated with steel standard samples. The image acquisitions were performed using conventional areal scan method covered with a square lattice of several 10,000 X-ray intensity measuring points. A relatively high beam current of $300 \mathrm{nA}$ was used to obtain a sufficient sensitivity. The beam conditions were maintained as $25 \mathrm{kV}$ to $300 \mathrm{nA}$, and the maximum count rate did not exceed 15,000 counts per second. The specimen microstructures sectioned from both the normal and defective areas were first analyzed in a conventional OM with visible light, and then precise EBSD analyses were performed. For determination of the deformation texture, the slices were sectioned from the surface $(s=1.0)$ and the center $(s=0.0)$. The through-thickness parameter $s$ indicates the position in the sheet with $S=2 \cdot \frac{a}{d}$, where $a$ is the spacing between the layer of interest and the center, and $d$ represents the total sheet thickness. The EBSD scanning area was $700 \times 1,000 \mu m^{2}$, in which approximately 3,000 grains were incorporated. From the orientation information of each grain, the orientation distribution functions (ODF) were derived, and the grain orientation spread signal (GS) was collected to distinguish the degree of deformation in the defective area. For all the EBSD measurements, only the signals with a confidence index over 0.1 were considered.

\section{Deformation texture calculation}

The viscoplastic self-consistent (VPSC) model developed by Lebensohn and Tome [30,31] was used to calculate the texture development during tensile elongation. In the VPSC model, each grain is assumed to be a viscoplastic ellipsoidal inclusion embedded in a homogeneous effective medium that represents an aggregate of the grains. The individual grain has its own crystallographic orientation and slip systems and can interact with the effective homogeneous medium. When strain develops, the grain rotates to an appropriate direction with a proper slip system and Taylor factor. By integrating all the rotations of the grains, we can predict the texture development after plastic deformation.

To perform this simulation, crystallographic orientation data and deformation tensors are required. For the grain orientations, we measured the grain orientations using EBSD analyses and extracted 5,000 grain orientations. The grain orientations were represented as Bunge Euler angles and were collected in an input file. Other simulation parameters including the lattice crystal information and the deformation gradient tensors were also prepared in a text file format. The stress response of the applied tensile strain was calculated using the Voce hardening model. The simulation results provided the orientation distribution functions and the Lankford R-values.

\section{Case description}

\section{Surface roughening after tensile elongation}

Figure 1 shows the appearance of the specimen surface after $5 \%$ tensile elongation. The same specimen before the tensile test and after tensile elongation over $10 \%$ did not contain any type of surface defect. Only the specimens that were elongated less than $10 \%$ exhibited typical striped patterns parallel to the rolling direction; thus, this defect is referred to as 


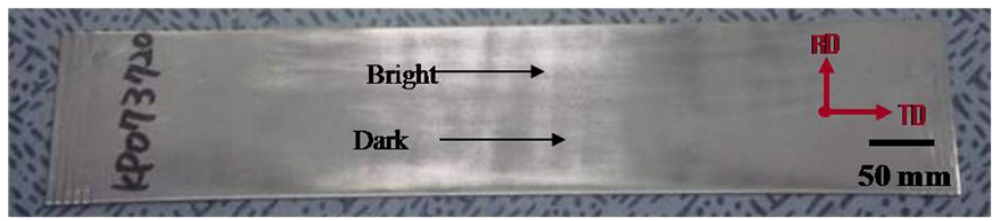

Figure 1 The line defects appeared in $2 \%$ elongated specimen. Bright and dark areas contrast each other.

a 'ghost line'. The stripe pattern was measured by a surface scanner and the pattern has a pitch of 2.5 to $3.0 \mathrm{~mm}$; the measured result is presented in Figure 2. The undulation profile is a direct evidence of the difference in height across the undulating surface. Moreover, the bright and dark contrast in Figure 1 is observed due to the scattering of visible light from the undulating surface. By matching the scanned profile and the visible positions of the bright and dark areas, it is found that the bright regions are peaks and the dark regions are troughs. The maximum height and pitch of the peaks were measured to be 31.3 and $3.0 \mathrm{~mm}$, respectively.

To investigate the microstructural details under the sample surface, the specimen area with the bright and dark contrast was sectioned in the thickness direction. A schematic of the sectioning is presented in Figure 3. Details of the section were explained in the preceding paragraph, and the microstructural features in this region will be presented in following section.

\section{Internal microstructure and chemical inhomogeneity}

The images in Figure 4 are optical micrographs of the surface, intermediate, and interior of the center of undulating regions of elongated specimen. In all of the regions, the microstructure contains pure ferritic grains without any second phase or carbide constituent. This microstructure is typical of ultra-low-grade carbon steels. All of the grains have equiaxed shapes, which is a result of completeness of recrystallization after the severe deformation and subsequent annealing process.

The sectioned specimen was treated with etchant described in the 'Experimental' section, which reacted with both the grain boundaries and internal elemental microsegregations. At the surface, the peaks and valleys did not exhibit any reaction to the etchant except for at the grain boundaries. However, at the intermediate depth $(1 / 4$ thickness from the center of the specimen), the peak region (bright area) exhibits the etching mark

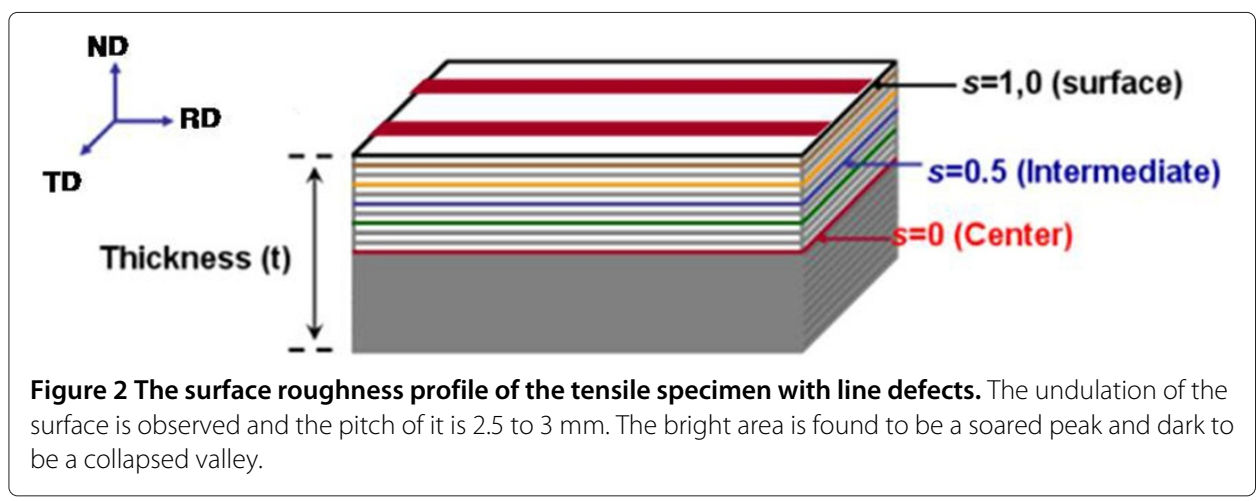




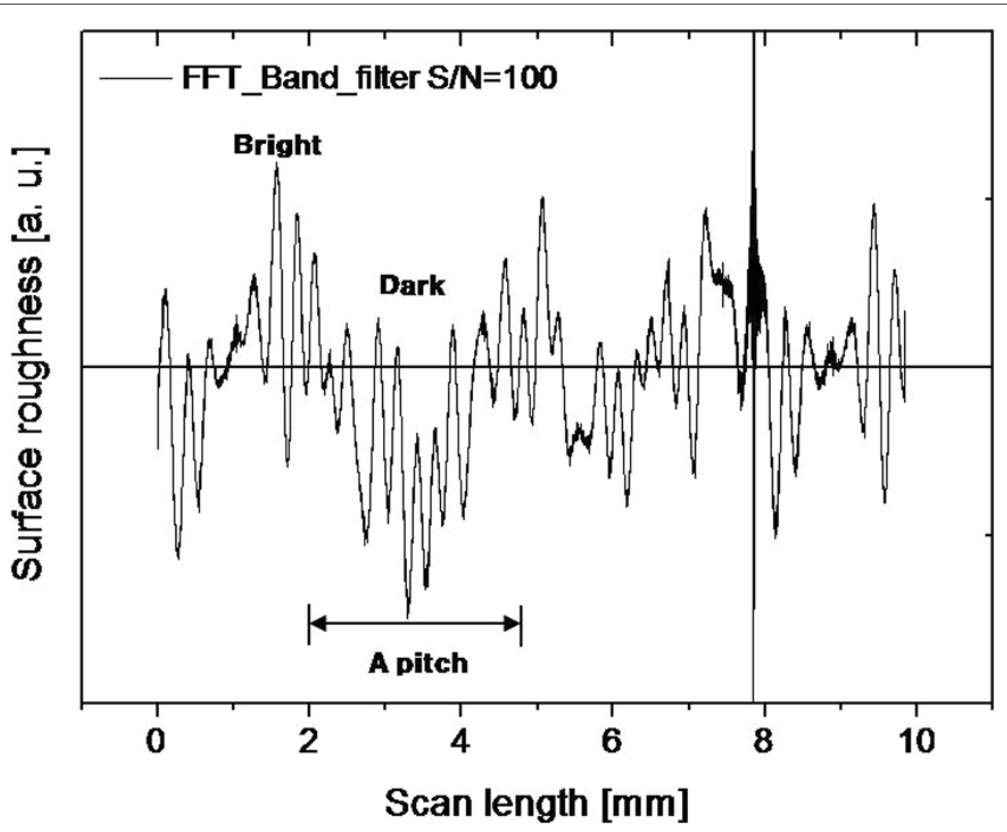

Figure 3 The schematic diagram of the sectioned parts for microstructural analyses from tensile specimen. Two line defects are marked with dark red lines into rolling direction.

that is transverse to the grain boundaries and has a much larger etched width (approximately a few microns). This effect may be the result of a reaction of segregated elements. In the middle of the specimen (the center region), the etched microstructure is composed of only clear ferrite grain boundaries, and the transverse line is not observed.

To further investigate the trace of the elemental segregation, we focused on the specific interface of the peak and valley regions. The same etchant was used for the metallographic observation. In Figure 5, the transverse etching lines exist only in the peak regions and terminates at boundaries of regions. The peak and valley regions are differentiated by their height on the surface and also by the internal microstructure underneath the surface. Because the etch line itself did not specify the element of the segregation, electron probe

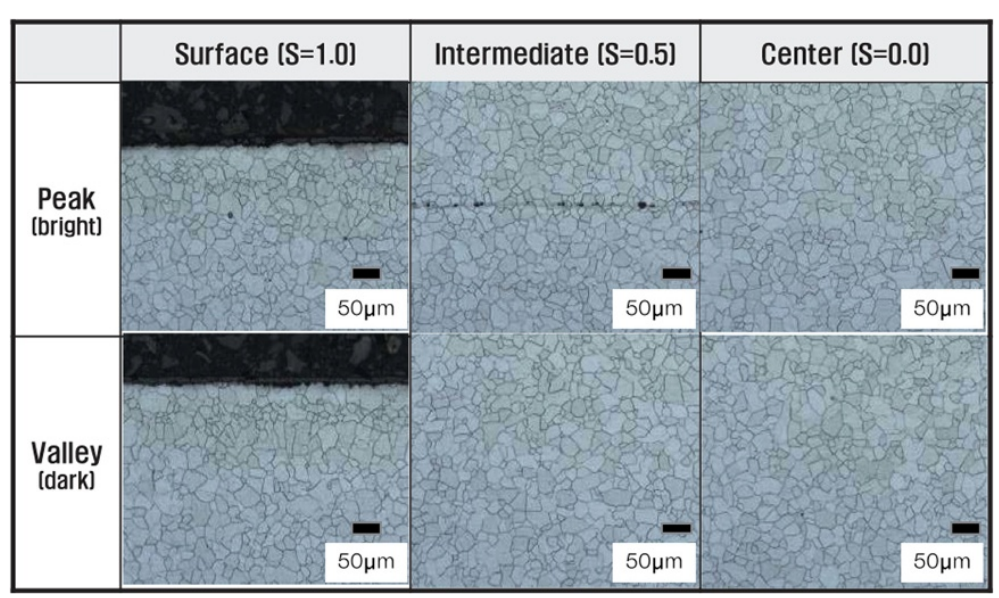

Figure 4 Optical micrograph of sectioned after tensile deformation. The abnormal etch line can be seen in the intermediate section of peak region. 


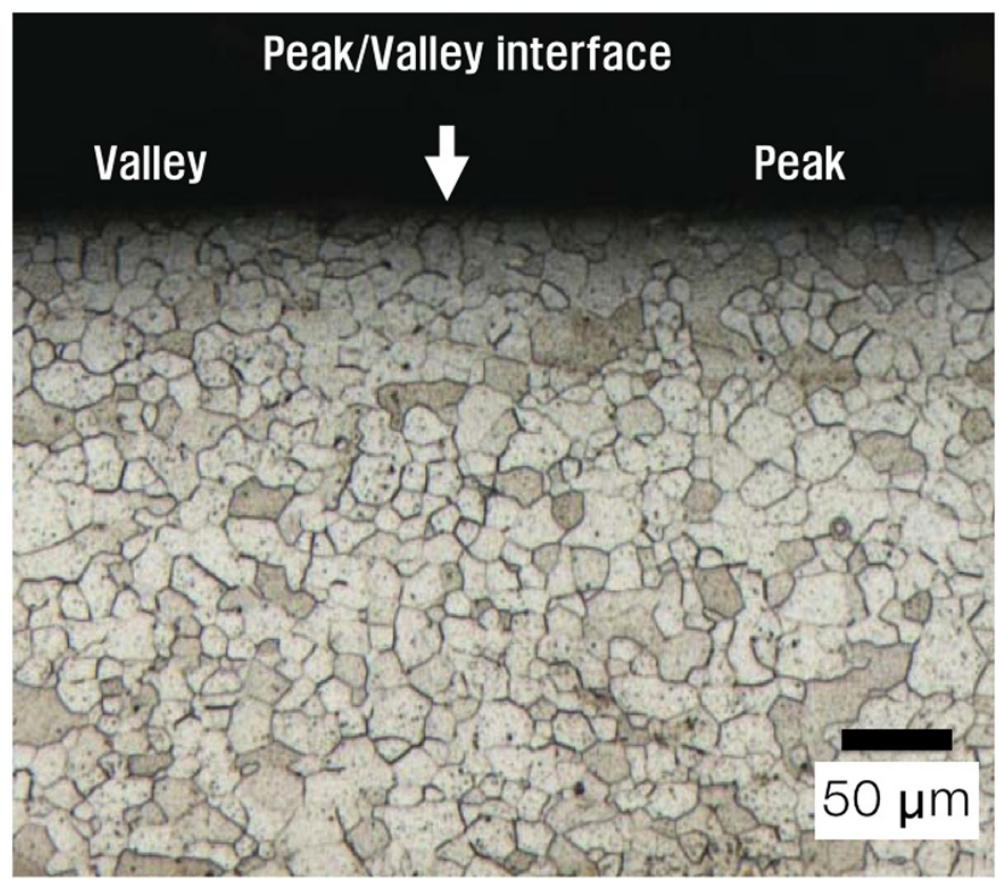

Figure 5 Cross-sectional microstructure of the interface region of the peak and valley area.

Intergranular line underneath the peak surface contrasts the clear grain under valley region.

microanalysis (EPMA) was performed using the concentration mapping technique. In the peak region, we created a microindentation mark near the etching line. Figure 6 presents a SEM micrograph of the line with the indentation mark, and Figure 7 presents a concentration mapping image. The vertical color code on the right indicates the phosphorous concentration on a relative concentration scale. Along the etched line, the concentration of $\mathrm{P}$ is higher than the non-etched region. Consequently, the distinct segregation of the phosphorous atoms along the line is noticeable.

\section{Deformation microstructure}

Figure 8 shows the grain orientation spread (GOS) value of the samples after plastic straining. The GOS value in EBSD analysis is calculated from the average misorientation between all of the pixel data points for a given grain. Then, the values for all of the grains in the measured area are given in terms of a color code. The upper row represents measurements from the samples of the peak (bright) region, and the lower row represents measurements from the valley (dark) region. The value changes inside a grain range between $0^{\circ}$ to $15^{\circ}$. Blue represents a GOS value of $0^{\circ}$, red represents greater than $5^{\circ}$, and black represents greater than $15^{\circ}$. In both the peak and valley regions, the intermediate section $(s=0.5)$ exhibits much darker colors (blue or black) than the surface $(s=0.0)$ or center $(s=1.0)$ sections. The color is almost black in the intermediate section of the valley.

From this GOS map, we observed that most of the deformation is concentrated in the valley region in the intermediate thickness section. The phosphorous segregation in Figure 5 is located in the peak region, which makes the ferrite grains of the segregated 


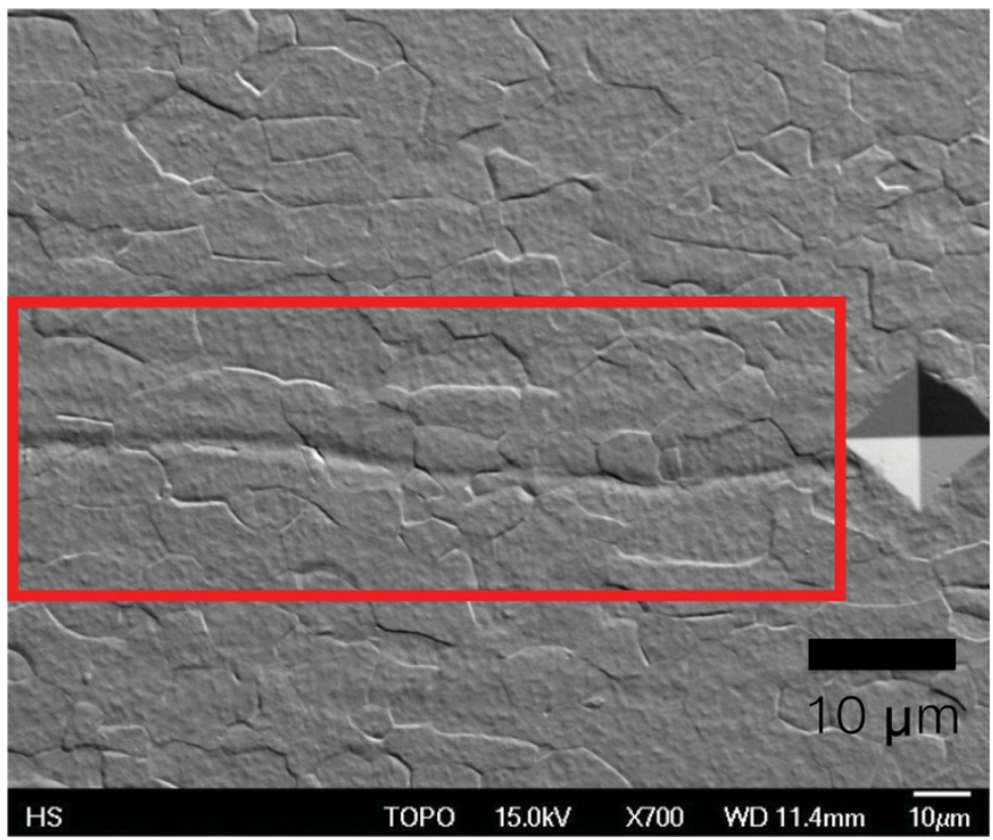

Figure 6 SEM micrographs from topological scanning of under the peak surface. The right diamond mark is a position indicator for the segregation.

region harder than those of the phosphorous-free zone. Thus, the valley without the segregation takes over most of the plastic deformation, resulting in a high GOS value and thus a high dislocation density. The strain heterogeneity due to elemental segregation affects the deformation textures after tensile elongation. Figure 9 shows the orientation density functions of the peak and valley. The measured samples were acquired from $2 \%$

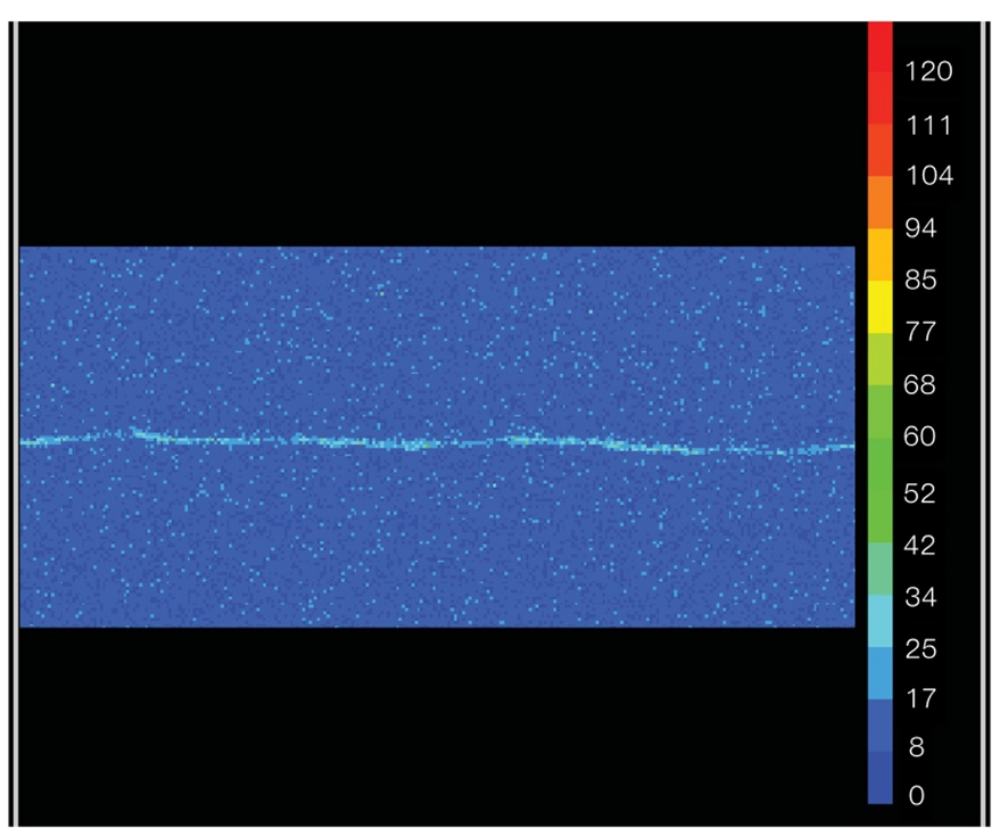

Figure 7 EPMA mapping results of the segregation line. 


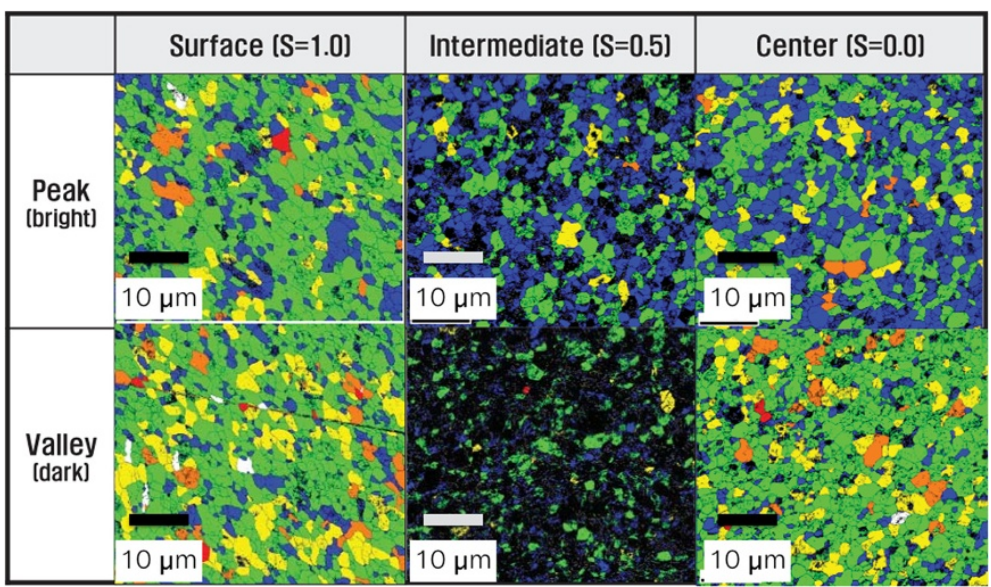

Figure 8 EBSD measurements for the sectioned samples from the tensile specimen. The image shows the grain orientation spread map (GOS). The blue color code has a GOS value of $0^{\circ}$ and the red one of $5^{\circ}$. The black color has a GOS value of $15^{\circ}$, which indicates highly deformed region with high dislocation density. Grain boundaries with angle larger than $15^{\circ}$ are also lined by black color in maps.

deformed specimen as shown in Figure 1. The ODF plots are represented with intensities on $\phi_{2}=45^{\circ}$. The two regions are different in that there is a phosphorus trace underneath the surface region. A developed $\gamma$ - fiber texture is observed in both regions. This result is typical for severe deformation and subsequent recrystallization behavior of ultralow-grade carbon steel. However, the fiber texture of the valley region deviates greatly from the ND //\{111\} fiber, and \{554\}[225] components are detected. After further plastic deformation over $10 \%$, the texture of both regions converged to be the same with a strong $\{554\}[225]$ component. Finally, the striped lines disappeared with this deformation.

\section{Discussion and evaluation}

In this section, we will discuss the effect of the deformation texture on the behavior of the surface-roughening defect with increasing tensile strain. Directly after a small amount of tensile deformation (i.e., less than 5\%), stripes were observed and these stripes disappeared with deformation greater than $10 \%$. The instant evolution and extinction of the
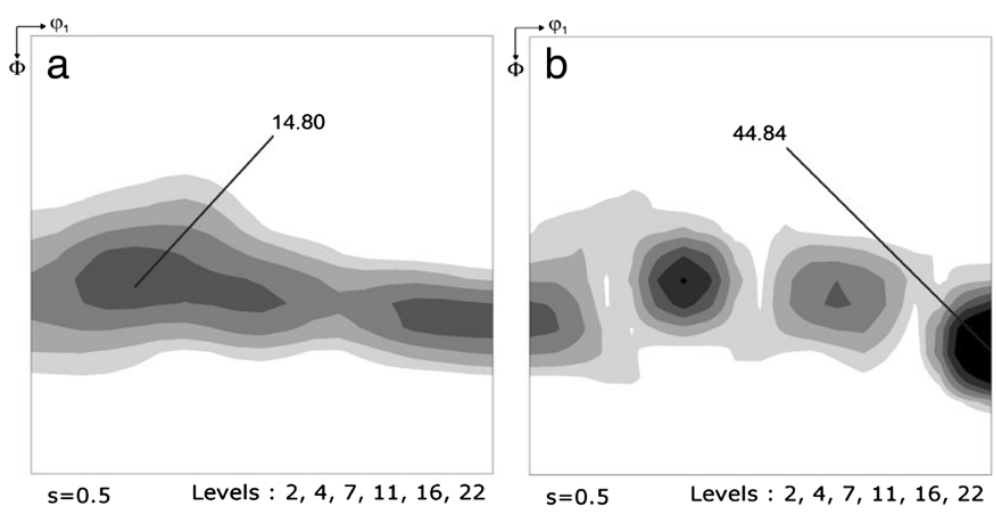

Figure 9 Experimentally determined orientation distributions for $5 \%$ deformed sheet. ODF plots along the r-fiber texture for peak (a) and valley (b) regions. Black lines are indicates maximum intensity value. 
defect lines are related to the deformation texture development underneath the defect the surface. From our results, it is clear that phosphorous atoms are segregated with a line type. Elemental $P$ is well known as a strong strengthening element in steel chemistry, and this element hardens the segregated region selectively. During tensile deformation, the strength difference between adjacent regions results in strain localization. We attempted to measure and quantify the localization of the straining in the microstructure by using the grain average misorientation (GAM) parameters from EBSD analysis. We used a GAM value of $1^{\circ}$ as the criterion for plastic deformation. In Table 2 , the plasticity index and deformation texture changes are prepared.

With the initial $5 \%$ of deformation strain, the strain is concentrated in the segregationfree region, and the GAM value at the valley is almost three times higher than the GAM value at the peak. This strain heterogeneity leads to a difference between the deformation textures of the ferrite grains: the grains in the valleys have a major \{554\}[225] component; however, those in the peak contain a major $\gamma_{2}$ component. To verify the effect of the amount of strain on the texture evolution, we perform a series of VPSC simulations for the uniaxial tensile condition. The simulation results are presented in Figure 10, which compare the texture components under increasing tensile strain. A distinct feature of the series of the texture is the development of $\{554\}[225]$ components. The $\{554\}[225]$ component is a typical deformation texture with rotating grains when the tensile strain is orthogonal to the rolling direction. Thus, the degree of development of the $\{554\}$ [225] component can be regarded as a measure of the tensile deformation. In the tensile experiment, the valley region has a strong $\{554\}[225]$ intensity over 40 , even under $5 \%$ strain. However, the VPSC simulation does not match the experimental results presented in Table 2. The texture calculated from the VPSC simulation, where the tensile strain is homogeneously distributed throughout the entire volume, has a $\{554\}[225]$ intensity of 38.77 even under $10 \%$ strain. This discrepancy is related to strain localization. The applied strain is effectively accumulated in the valley region, i.e., in the segregation-free region, and the effective strain on this region is over $10 \%$, even if only $5 \%$ elongation is applied macroscopically.

A typical property affected by texture variation is the Lankford factor, i.e., R-value, which represents physical anisotropy of a sheet specimen. This factor is a measure of resistance to substantial thinning of the sheet thickness, i.e., the plastic strain ratio of the width to thickness direction. A large R-value indicates high resistance to thinning of the thickness

$$
R=\frac{\ln \left(\frac{w_{0}}{w}\right)}{\ln \left(\frac{t_{0}}{t}\right)}=\frac{\epsilon_{w}}{\epsilon_{t}}
$$

where $w_{0}$ and $w$ are the initial and final widths, respectively, and $t_{0}$ and $t$ are the initial and final thicknesses, respectively. Because the R-value of a rolled sheet varies with orientation

Table 2 Strain localization and change of deformation texture

\begin{tabular}{lccc}
\hline & \multicolumn{3}{c}{ Stain } \\
\cline { 2 - 4 } & $\mathbf{5 \%}$ & $\mathbf{7 \%}$ & $\mathbf{1 0 \%}$ \\
\hline Strain index $\left(\mathrm{GAM}>1^{\circ}\right)$ at peak & 10.5 & 15.8 & 27.8 \\
Strain index $\left(\mathrm{GAM}>1^{\circ}\right)$ at valley & 28.1 & 29.8 & 31.3 \\
Major texture component at peak & $\gamma_{2}$ & $\gamma_{2}$ & $\{554\}[225]$ \\
Major texture component at valley & $\{554\}[225]$ & $\{554\}[225]$ & $\{554\}[225]$ \\
\hline
\end{tabular}




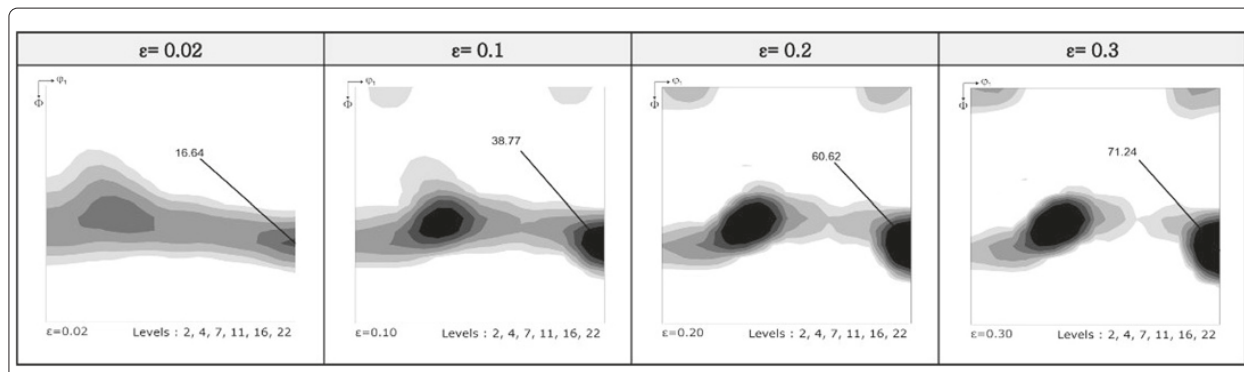

Figure 10 Simulated ODF plot with series of tensile straining.

in the plane of the sheet, we calculate the R-value profile at different angles to the rolling direction. The same VPSC model was used for simulating the input of measured EBSD datasets. In Figure 11, the R-values are plotted for the initial and 5\% deformed sheets. The grains with $\{554\}$ [225] texture increase, and the plastic anisotropy and R-value of $90^{\circ}$ also increase. Therefore, the thickness reduction of the grains is effectively prohibited because these grains have higher R-values than the adjacent grains with $\gamma$-fiber texture. At the initial stage of deformation, as stated previously, deformation mainly occurs in the segregation-free area (valley), and the $\{554\}[225]$ texture can be developed locally, which was demonstrated by the experimental EBSD analysis (in Figure 9). In contrast, deformation in the segregated area (peak) is hindered, and the strong $\gamma$-fiber texture inherited from the recrystallization remains. Because of the texture heterogeneity, the thickness reduction of the grains are different from each other, thus providing an explanation for the surface undulation. When plastic strain is continued to be applied, the remaining $\gamma$-fiber texture will likely broke and rotated to $\{554\}[225]$ direction, and both the peak and valley have a common $\{554\}[225]$ component over $10 \%$ deformation in Table 2 . Consequently,

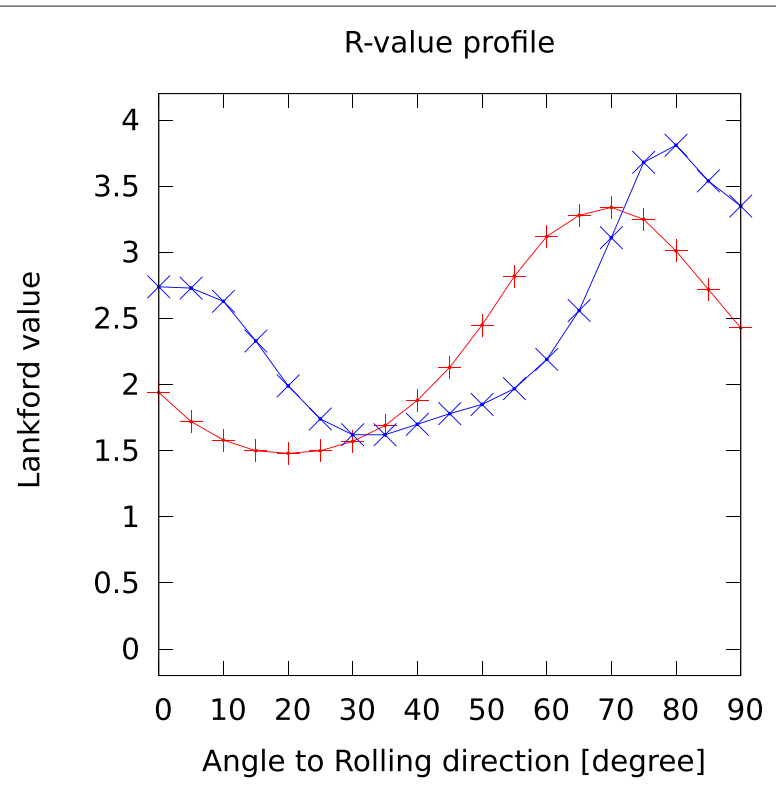

Figure 11 Calculated R-value profile from the series of VPSC simulations. The plus and multiplication symbols indicate initial and $5 \%$ deformed state, respectively. 
the texture heterogeneity disappears, and the thickness profile becomes flat. The 'ghost line' defect, that appears at the initial stage of deformation, is not visible.

\section{Conclusions}

The results of our investigation clarify the cause of the surface undulation defects of steel sheets during press forming plastic deformation. The heterogeneous distribution of the phosphorus alloying element is the main cause of the defect. The elemental phosphorus segregation layer is inherited from the hot-band and remains after the final annealing process of the cold rolled sheet. This segregation induces localization of plastic deformation, and the deformation texture is uneven. The following conclusions were drawn concerning the defect:

1. The ferrite grains in the segregation region are harder than normal grains, and most of the plastic strain is concentrated in the segregation-free grains during deformation of the final sheet product.

2. Owing to the heterogeneous distribution of the plastic strain, the textures vary between regions. The developed \{554\}[225] component in the segregation-free region gives a higher $\mathrm{R}$-value than the normal $\gamma$-fiber texture in the segregated region.

3. The different Lankford values of the different regions cause a local thickness variation during plastic deformation. However, when further deformation proceeds all of the texture components converge to be the same with the $\{554\}$ [225] component, and the heterogeneous texture disappears. Then, the surface undulation can no longer be observed.

Competing interests

The authors declare that they have no competing interests.

\section{Authors' contributions}

NHG conducted the VPSC simulations, analysed the experimental ODFs, and led the writing of the manuscript. CK analysed the microstructure and performed mechanical deformation tests. Both authors read and approved the final manuscript.

Received: 9 May 2014 Accepted: 2 September 2014

Published online: 10 October 2014

\section{References}

1. Rocabois P, Lehmann J, Gatellier C, Teres J (2003) Non-metallic inclusion entrapment by slags: laboratory investigation. Ironmaking steelmaking 30(2):95-100

2. Makimattila S, Ristolainen $E$, Sulonen M, Lindroos V (1985) The effect of the intermetallic layer on the adherence of a hot-dip galvanized coating. Scripta Metall 19(2):211-214

3. Nakamori T, Adachi Y, Arai M, Shibuya A (1995) Coating adhesion and interface structure of galvannealed steel. ISIJ Int 35(12):1494-1501

4. Nakamori T, Adachi Y, Toki T, Shibuya A (1996) Effect of microstructure of base steel on fe-zn alloy growth during galvanizing of an interstitial free steel. ISIJ Int 36(2):179-186

5. Hong M-H, Saka H (2004) Fib and tem observations of defects in hot-dip zinc coatings. J Electron Microsc 53(5):545-552

6. Jalel Ben nasr, Snoussi A, Bradai C, Halouani F (2008) Effect of the withdrawal speed on the thickness of the zinc layer in hot dip pure zinc coatings. Mater Lett 62(14):2150-2152

7. Hong M, Paik D (2009) Effect of substrate surface polishing on galvannealing characteristics of a mild if and an hsif steel. Ironmaking Steelmaking 36(3):234-240

8. Azimi A, Ashrafizadeh F, Toroghinejad M, Shahriari F (2012) Metallurgical analysis of pimples and their influence on the properties of hot dip galvanized steel sheet. Engineering Failure Analysis 26:81-88

9. Osakada K, Oyane M (1971) On the roughening of free surface in deformation processes. Bull JSME 14(68):171-177

10. Raabe D, Sachtleber M, Weiland H, Scheele G, Zhao Z (2003) Grain-scale micromechanics of polycrystal surfaces during plastic straining. Acta Materialia 51(6):1539-1560

11. Wichern C, De Cooman B, Van Tyne C (2004) Surface roughness changes on a hot-dipped galvanized sheet steel during deformation at low strain levels. Acta materialia 52(5):1211-1222 
12. Wichern C, De Cooman B, Van Tyne C (2005) Surface roughness of a hot-dipped galvanized sheet steel as a function of deformation mode. J Mater Process Tech 160(3):278-288

13. Brochu M, Yokota T, Satoh S (1997) Analysis of grain colonies in type 430 ferritic stainless steels by electron back scattering diffraction (ebsd). ISIJ Int 37(9):872-877

14. Guangnan C, Huan S, Shiguang H, Baudelet B (1990) Roughening of the free surfaces of metallic sheets during stretch forming. Mater Sci Eng 128(1):33-38

15. Huh M-Y, Engler O (2001) Effect of intermediate annealing on texture, formability and ridging of $17 \% \mathrm{Cr}$ ferritic stainless steel sheet. Mater Sci Eng 308(1):74-87

16. Becker R (1998) Effects of strain localization on surface roughening during sheet forming. Acta Materialia 46(4):1385-1401

17. Schaefer C, Song J, Gottstein G (2009) Modeling of texture evolution in the deformation zone of second-phase particles. Acta Materialia 57(4):1026-1034

18. Chakraborty A, Ray R (2009) Influence of microstructure and texture on the formability character of industrially produced galvannealed coatings on three interstitial free steels. Surf Coating Tech 203(13):1756-1764

19. Hamada J-I, Matsumoto Y, Fudanoki F, Maeda S (2003) Effect of initial solidified structure on ridging phenomenon and texture in type 430 ferritic stainless steel sheets. ISIJ Int 43(12):1989-1998

20. Humphreys F (1979) Local lattice rotations at second phase particles in deformed metals. Acta Metallurgica 27(12):1801-1814

21. Humphreys F, Kalu P (1990) The plasticity of particle-containing polycrystals. Acta Metallurgica Et Materialia 38(6):917-930

22. Li S, Van Houtte P, Kalidindi SR (2004) A quantitative evaluation of the deformation texture predictions for aluminium alloys from crystal plasticity finite element method. Model Simulat Mater Sci Eng 12(5):845

23. Radhakrishnan B, Sarma G (2004) The effect of coarse non-deformable particles on the deformation and static recrystallization of aluminium alloys. Phil Mag 84(22):2341-2366

24. Rangarajan V, Cheng C, Franks L (1993) Texture in the delta Fe-Zn phase formed in galvanneal coatings. Surf Coating Tech 56(3):209-214

25. Savoie J, Jonas J (1994) Simulation of the deformation textures induced by deep drawing in extra low carbon steel sheets. Acta metallurgica et materialia 42(12):4101-4116

26. Shin $\mathrm{H}-J$, An J-K, Park SH, Lee DN (2003) The effect of texture on ridging of ferritic stainless steel. Acta Materialia 51(16):4693-4706

27. Sidor JJ, Petrov RH, Kestens LA (2011) Microstructural and texture changes in severely deformed aluminum alloys. Mater Char 62(2):228-236

28. Stoudt M, Hubbard J (2005) Analysis of deformation-induced surface morphologies in steel sheet. Acta materialia 53(16):4293-4304

29. Zhao Z, Radovitzky R, Cuitino A (2004) A study of surface roughening in fcc metals using direct numerical simulation. Acta Materialia 52(20):5791-5804

30. Lebensohn R, Tome C (1994) A self-consistent viscoplastic model: prediction of rolling textures of anisotropic polycrystal. Mater Sci Eng 175(1):71-82

31. Lebensohn R, Tome C (1993) A self-consistent anisotropic approach for the simulation of plastic deformation and texture development of polycrystals: application to zirconium alloys. Acta Metallurgica et Materialia 41(9):2611-2624

doi:10.1186/s40192-014-0023-7

Cite this article as: Goo and Kang: Analysis of the surface-roughening phenomenon in P-added bake-hardened stee sheets. Integrating Materials and Manufacturing Innovation 2014 3:23.

\section{Submit your manuscript to a SpringerOpen ${ }^{\circ}$ journal and benefit from:}

- Convenient online submission

Rigorous peer review

- Immediate publication on acceptance

- Open access: articles freely available online

- High visibility within the field

- Retaining the copyright to your article

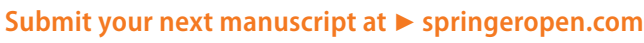

